\title{
Influence of the Type of Fiber on the Structure and Viscoelastic Relaxations in Composites Based on a Metallocenic Ethylene-1-octene Copolymer
}

\author{
María L. Cerrada, ${ }^{\dagger}$ Rosario Benavente, Galina Zamfirova, ${ }^{\dagger \dagger}$ and Ernesto PÉReZ \\ Instituto de Ciencia y Tecnología de Polímeros (CSIC), Juan de la Cierva 3, 28006 Madrid, Spain
}

(Received October 9, 2001; Accepted December 22, 2001)

\begin{abstract}
Several composites of a copolymer of ethylene and 1-octene, synthesized with a metallocene catalyst, have been prepared with a $5 \%$ in weight of different types of fiber. The effect of the fiber on the crystalline structure and on the viscoelastic response is analyzed. The role of the fiber on crystallite development is discussed based on WAXS, SAXS, optical microscopy and DSC experiments. The viscoelastic behavior is modified by incorporation of the fiber when compared with the plain copolymer. Thus, both the intensity and location of the $\gamma, \beta$ and $\alpha$ relaxations are dependent on the introduction of the fiber. The $\beta$ relaxation is assigned to the glass transition temperature, in agreement with the calorimetric results (DSC and MDSC) in the copolymer. Moreover, the stiffness is increased in the composites above the glass transition temperature of the copolymer, allowing the analysis of the viscoelastic behavior up to temperatures well inside the melting region of the copolymer crystals, and thus enlarging substantially the service temperature of these composites.
\end{abstract}

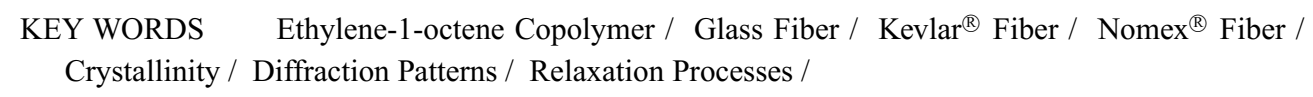

The use of metallocene catalysts has allowed a very rapid development in the field of polyolefins. These catalysts present single-site characteristics (and very high activities) and thus all the sites produce nearly the same chain architecture, ${ }^{1}$ leading to polymers with narrow molecular weight distributions, and, in the case of copolymers with $\alpha$-olefins, the side branches are randomly distributed in the polymer backbone. If the comonomer content is high enough, around $4 \mathrm{~mol} \%$ depending upon the catalyst system used, a material exhibiting dual characteristics of plastic and elastomeric behavior can be achieved.

An enhance of the mechanical and thermal properties required for load bearing engineering applications can be achieved by the incorporation of disperse fibers into polymers. This change in the mechanical and thermal behavior is due to several factors, such as variation in the mobility of the macromolecules in the boundary layers, the orientation influence of the fiber surface, the different types of fiber-polymer interactions, as well as the effect of fibers on the structure of the polymers. ${ }^{2,3}$ Glass fibers are probably the most common of all reinforcing fibers for polymer matrix composites. Their principal advantages are their low cost and high strength. $\operatorname{Kevlar}^{\circledR}$ is one of the most important manmade organic fibers ever developed. Fibers of Kevlar ${ }^{\circledR}$ consist of long molecular chains produced from polyparaphenylene terephthalamide. The chains are highly oriented with strong interchain bonding lead- ing to a unique combination of properties, making them very useful in a wide variety of industrial applications. Other kind of reinforcement frequently used are fibers of Nomex ${ }^{\circledR}$ that inhere in long rigid molecular chains produced from polymetaphenylene diamine. They do not flow or melt upon heating, providing consequently a very good dimensional stability and excellent heat resistance. As disadvantage of these $\operatorname{Kevlar}^{\circledR}$ and Nomex ${ }^{\circledR}$ fibers is their high cost. It is well known that fibers can act as a nucleating agent modifying the process of crystallization ${ }^{4-6}$ provoking a reduction in the crystallization time. ${ }^{7}$ On the other hand, a reduction in size and perfection of crystallites in composites compared with the isolated matrix has been pointed out in PET. ${ }^{8}$

A good balance between rigidity and elasticity might be attained by incorporation of fibers to ethylene copolymers with $\alpha$-olefins contents higher than $4 \mathrm{~mol} \%$ depending upon either comonomer or fiber type or, on the other hand, fiber contents, and therefore a new type of thermoplastic elastomers could be obtained with higher resistance to creep under stress by reducing deformation and deflection under load. Accordingly, reliable studies on structure-properties relationships are necessary to be able to achieve such tailored materials and to learn if the use of polymeric fibers within this kind of matrix is economically worthy. Therefore, the aim of this work is to investigate the effect on the crystalline morphology and viscoelastic behavior of

\footnotetext{
${ }^{\dagger}$ To whom correspondence should be addressed (Phone: +34-91-5622900, Fax: +34-91-5644853, E-mail: ictcg26@ictp.csic.es).

${ }^{\dagger}$ Permanent address: Higher Institute of Transport Engineering “T. Kableshkov”. Geo Milev str., 158, 1574 Sofia, Bulgaria.
} 
the incorporation of different types of fiber into a metallocenic matrix. The interaction of fiber and matrix has been analyzed by WAXS, SAXS and optical microscopy experiments performed at room temperature and followed along melting by DSC. In addition, the assignment of the $\beta$ relaxation to the glass transition is discussed.

\section{EXPERIMENTAL}

A commercial ethylene-1-octene copolymer (CEO) with a $9.3 \mathrm{~mol} \%$ comonomer content is analyzed in the current paper and has been supplied by Exxon Chemical. Three distinct types of fiber were utilized in the preparation of the different composites: chopped strands of E glass fibers of $6 \mathrm{~mm}$ long, grade E-11 supplied by Cristalera Española S. A. Other kind of reinforcement was a continuous Kevlar ${ }^{\circledR}$ para-aramid fiber that was chopped up to achieve a length of around $10 \mathrm{~mm}$. And the third type used was a continuous Nomex ${ }^{\circledR}$ fiber that was also chopped to attain discrete filaments of about $10 \mathrm{~mm}$ long. Kevlar ${ }^{\circledR}$ and Nomex ${ }^{\circledR}$ were supplied by Dupont.

Composites with a content in fiber of $5 \%$ in weight, labeled as CEOGF5, CEOK5, CEON5, for glass, Kevlar ${ }^{\circledR}$ and Nomex ${ }^{\circledR}$ fibers respectively, were prepared in a Haake Rheocord 9000 at $150^{\circ} \mathrm{C}$ and at $40 \mathrm{rpm}$ for $10 \mathrm{~min}$. After blending and homogenization of the two different components, sheet specimens were obtained as films by compression molding in a Collin press between hot plates $\left(130^{\circ} \mathrm{C}\right)$ at a pressure of $1.5 \mathrm{MPa}$ for $10 \mathrm{~min}$, and subsequently quenching to room temperature.

Calorimetric analyses were carried out in a PerkinElmer DSC7 calorimeter, connected to a cooling system and calibrated with different standards. The sample weights ranged from 8 to $10 \mathrm{mg}$. A temperature range from $10^{\circ}$ to $130^{\circ} \mathrm{C}$ has been analyzed on the as molded quenched specimens and the used heating rate was $8^{\circ} \mathrm{C} \mathrm{m^{-1 }}$. Moreover, an additional fast cooling $\left(100^{\circ} \mathrm{C} \mathrm{min}{ }^{-1}\right)$ and a further melting from -70 to $130^{\circ} \mathrm{C}$ at $20^{\circ} \mathrm{C} \mathrm{min}-1$ were performed to estimate the glass transition temperature of these composites. For crystallinity determinations, a value of $290 \mathrm{~J} \mathrm{~g}^{-1}$ has been taken as the enthalpy of fusion of a perfectly crystalline material. ${ }^{9}$

Wide-angle X-Ray diffraction patterns were recorded in the reflection mode at room temperature by using a Philips diffractometer with a Geiger counter, connected to a computer. Ni-filtered $\mathrm{Cu}-K_{\alpha}$ radiation was used. The diffraction scans were collected over a period of $20 \mathrm{~min}$ in the range of $2 \theta$ values from 3 to 43 degrees, using a sampling rate of $1 \mathrm{~Hz}$. The goniometer was calibrated with a silicon standard.

The crystalline diffractions and the amorphous component have been separated with a fitting program which allows to estimate the crystallinity of the samples. The baseline has been taken just as a straight line in the $2 \theta$ range from 10 to 30 degrees, and no further correction has been applied. The different diffraction peaks were fitted to Voigt functions. The amorphous peak of the different samples was found to be centered at about $2 \theta \approx 19.5$ degrees.

The samples were also studied by small-angle XRay scattering, SAXS, employing synchrotron radiation (with $\lambda=0.150 \mathrm{~nm}$ ) in the beamline A2 at HASYLAB (Hamburg, Germany). A SAXS linear positionsensitive detector was used at a distance of $235 \mathrm{~cm}$ from the sample, and was calibrated with the different orders of the long spacing of rat-tail cornea $(L=65 \mathrm{~nm})$. It was found to cover a spacings range from 5 to $55 \mathrm{~nm}$.

An Amplival optical microscope (Carl Zeiss Jena) was used for the morphology studies to ascertain the incorporation mode of a small amount of fiber and the morphological variation by changing the type of such a fiber. The samples were placed between glass slides, melted above the melting point, quenched down to around $66^{\circ} \mathrm{C}$ where isothermal crystallization for three hours was allowed and examined in the optical microscope under crossed polarizers. The diameter of the fibers has been also estimated, as listed in Table I.

Viscoelastic properties were measured with a Polymer Laboratories MK II dynamic mechanical thermal analyzer working in a tensile mode. The real, $E^{\prime}$, and imaginary, $E^{\prime \prime}$, components of the complex modulus and the loss tangent, $\tan \delta$ of each sample were determined at $1,3,10$ and $30 \mathrm{~Hz}$, over a temperature range from -150 to $100^{\circ} \mathrm{C}$, at a heating rate of $1.5^{\circ} \mathrm{C} \mathrm{min}^{-1}$. The apparent activation energy values were estimated on loss modulus according to an Arrhenius-type equation, employing an accuracy of $1{ }^{\circ} \mathrm{C}$ in the temperature assignment of loss modulus maxima. The frequency dependence with temperature in the relaxation mechanism associated to the glass transition has been also considered to follow an Arrhenius behavior though it is due to cooperative motions. ${ }^{10}$ This approximation can be made without a significant error, since the analyzed frequencies are low enough to be fitted to such a linear behavior just mentioned. However, if measurements were carried out in a wider frequency range, the linear dependence would not be longer exhibited since the non-Arrhenius inherent character of this process. ${ }^{10}$

A Vickers indentor attached to a Leitz microhardness, $\mathrm{MH}$, tester was used to carry out microindentation measurements. Experiments were undertaken at $27^{\circ} \mathrm{C}$. A contact load of $0.98 \mathrm{~N}$ and a contact time of 
Table I. Fiber characteristics and DSC values of the enthalpies of melting and crystallinities, and WAXS and SAXS data estimated for the metallocene ethylene-1-octene copolymer and its composites with the different fibers in a content of 5\% in weight ${ }^{\mathrm{a}}$

\begin{tabular}{|c|c|c|c|c|c|c|c|c|c|}
\hline \multirow{2}{*}{ Sample } & \multirow{2}{*}{$\begin{array}{c}\text { Type of } \\
\text { fiber }\end{array}$} & \multirow{2}{*}{$\begin{array}{c}\text { Diameter } \\
\text { of fiber } \\
\mu \mathrm{m}\end{array}$} & \multirow{2}{*}{$\begin{array}{l}\text { Density of } \\
\frac{\text { fiber }^{\mathrm{b}}}{\mathrm{g} \mathrm{cm}^{-3}}\end{array}$} & \multirow{2}{*}{$\frac{\Delta H_{\mathrm{m}}{ }^{\text {normalized }}}{\mathrm{Jg}^{-1}}$} & \multirow{2}{*}{$f_{\mathrm{c}}^{\mathrm{DSC}}$} & \multicolumn{3}{|c|}{$f_{\mathrm{c}}$ WAXS } & \multirow{2}{*}{$\frac{L^{\mathrm{SAXS}}}{\mathrm{nm}}$} \\
\hline & & & & & & total & disordered & orthorhombic & \\
\hline CEO & - & - & - & 53 & 0.18 & 0.23 & 0.08 & 0.15 & 12.0 \\
\hline CEOGF5 & Glass fiber & 9 & 2.6 & 58 & 0.20 & 0.30 & 0.07 & 0.23 & 11.8 \\
\hline CEOK5 & Kevlar $^{\circledR}$ & 12 & 1.5 & 57 & 0.20 & 0.31 & 0.07 & 0.24 & 12.2 \\
\hline CEON5 & Nomex ${ }^{\circledR}$ & 16 & 0.7 & 61 & 0.21 & 0.31 & 0.09 & 0.22 & 12.1 \\
\hline
\end{tabular}

${ }^{\mathrm{a}}$ Estimated errors: enthalpies $\pm 4 \mathrm{~J} \mathrm{~g} \mathrm{~g}^{-1} ; f_{\mathrm{c}}^{\mathrm{WAXS}} \pm 0.04 ; L^{\mathrm{SAXS}} \pm 0.4 \mathrm{~nm}$; diameter of fiber $\pm 1 \mu \mathrm{m}$. The values of $\Delta H_{\mathrm{m}}$ and crys-

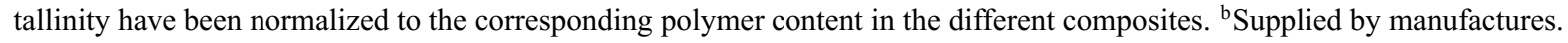

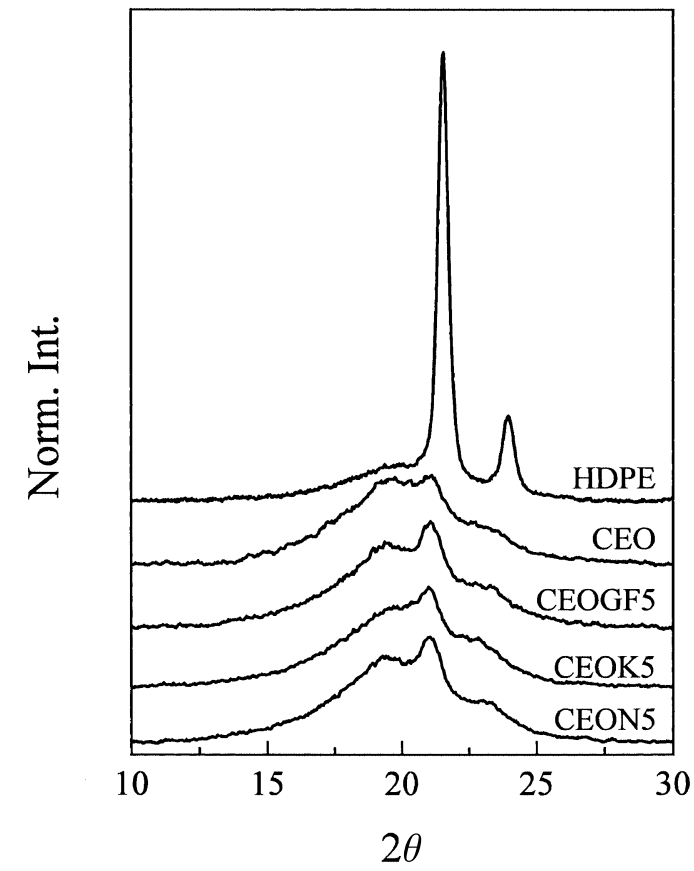

Figure 1. X-Ray diffraction patterns, at room temperature, of the different samples. From top to bottom: CEO, CEOGF5, CEOK5, CEON5. A metallocenic HDPE pattern has been added on the top for comparative reasons.

$25 \mathrm{~s}$ were employed. MH values (in MPa) were calculated according to the relationship:

$$
M H=2 \sin 68^{\circ} \mathrm{P} / d^{2}
$$

where $P$ (in $\mathrm{N}$ ) is the contact load and $d$ (in $\mathrm{mm}$ ) is the diagonal length of the projected indentation area. As will be shown bellow, this technique was used to test the homogeneity in the composites.

\section{RESULTS AND DISCUSSION}

\section{Crystalline Structure}

Figure 1 displays the different X-Ray patterns found at room temperature for all of the specimens analyzed. Polyethylene crystallizes in the typical orthorhombic lattice. ${ }^{11,12}$ Figure 1 shows a considerable distortion of the polyethylene crystal lattice due to the presence of comonomer in CEO, $9.3 \mathrm{~mol} \%$ in 1-octene, though the (110) and (200) diffractions peaks of the orthorhom- bic unit cell are still observed. Compared to a metallocenic polyethylene homopolymer (upper pattern in Figure 1), a very significant decrease of the intensity in the crystalline diffractions is exhibited, in such a way that the (200) peak becomes a shoulder in the CEO pattern. In addition, diffractions are broadened and shifted to lower angles indicating a diminishment in the crystallites size and less perfect crystals, respectively because the branches are not incorporated into the crystallites. Exclusively, the methyl branches are included in the lattice at a substantial degree $e^{13-17}$ and, in a small proportion, the ethyl ones have been also found in crystalline environments. ${ }^{18-20}$ Moreover, for high comonomer contents, like in the current case, besides the (110) and (200) orthorhombic reflections, a third crystalline reflection, centered at about $4.53 \AA$, is observed. The origin of this extra reflection is not clear, since it can be ascribed to either monoclinic or hexagonal crystals. ${ }^{21-25}$ It seems evident, however, that it arises from very imperfect crystals, ${ }^{26,27}$ probably with a bundle-like structure instead of a lamellar one. Therefore, we will designate it as "disordered" crystals or "disordered" modification.

The composites with the different types of fiber exhibit rather similar diffractograms than the copolymer matrix. However, the introduction of the fiber provokes an important increase in the intensity of the (110) diffraction, suggesting the participation of the fibers on the crystallization process in some extension, acting as nucleation agents. Accordingly, the orthorhombic contribution to the crystallinity estimated from data in Figure 1 increases in the composites by comparison with the unreinforced CEO, being similar for all of the composites, as listed in Table I. The differences in the "disordered" crystalline phase are, however, well inside the determination error in all the samples. The deconvolution corresponding to two of the samples is presented in Figure 2.

The Lorentz-corrected SAXS profiles are displayed in Figure 3. Though the 1-octene content in the CEO is high, $9.27 \mathrm{~mol} \%$, long spacings are exhibited either for the plain copolymer or the composites at room tem- 


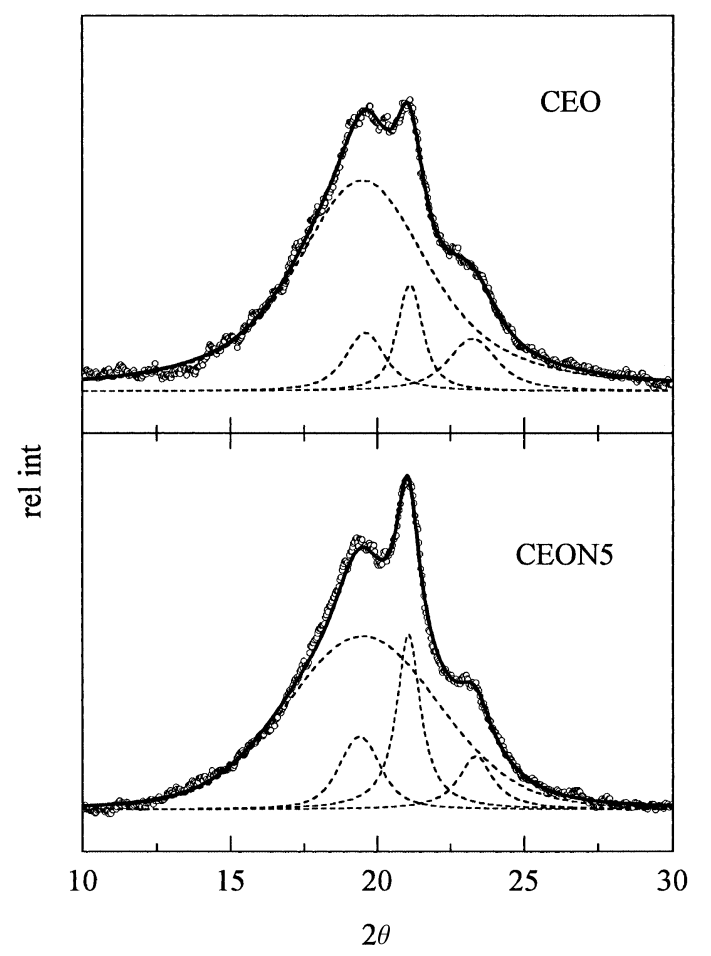

Figure 2. Deconvolution of CEO and CEON5 X-Ray diffraction patterns (symbols) into the amorphous component, the disordered crystalline one, the (110) and (200) orthorhombic peaks (dot lines) and the overall fit (solid line).

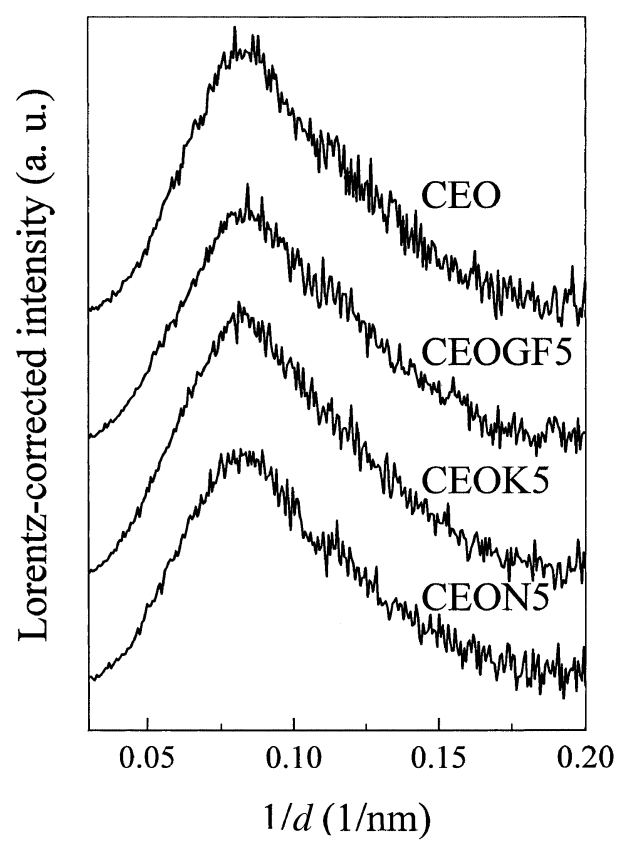

Figure 3. Lorentz-corrected SAXS profiles, at ambient temperature, for the different samples. From top to bottom: CEO, CEOGF5, CEOK5, CEON5.

perature. Such a long spacing is attributed to the presence of lamellar crystals. Its value is quite similar for all the samples, as reported in Table I. It seems that a slightly higher long spacing is developed for those composites reinforced with polymeric fibers (CEOK5 and CEON5), though the different values are inside the

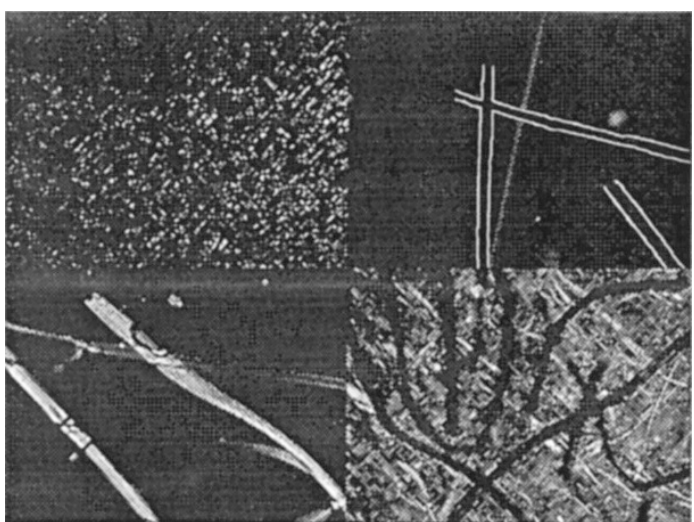

Figure 4. Morphology of different samples crystallized at $66^{\circ} \mathrm{C}$ for $3 \mathrm{~h}$ : CEO (upper left), CEOGF5 (upper right), CEON5 (lower left) and CEOK5 (lower right). The total width of each photograph frame represents $380 \mu \mathrm{m}$.

experimental error.

Figure 4 shows the optical micrographs for the different samples analyzed. The upper left picture, related to CEO plain copolymer, displays the morphology expected, i.e., very small spherulites of around 14-17 $\mu \mathrm{m}$ with no banding pattern because of the high content in 1-octene within CEO. Crystallization was performed under the same temperature and time for the different composites (glass fiber: upper right picture; Nomex ${ }^{\circledR}$ : lower left picture; and $\operatorname{Kevlar}^{\circledR}$ : lower right picture). In CEOGF5 and CEON5, an increase of the nucleation rate is observed but additional morphological details are not possible to be attained because of the darkness in the matrix since a slightly higher ratio of smallest spherulites is developed in these two composites in comparison with pure CEO, as DSC results corroborate by the higher intensity of the heat flow in the temperature range of $20-55^{\circ} \mathrm{C}$. The difference found between these two type of fibers is that the Nomex ${ }^{\circledR}$ one exhibits birefringence and the glass fiber not. In CEOK5, morphological details could not be obtained since some Kevlar ${ }^{\circledR}$ fibers have undergone a peeling process, probably, along the mixing step. Consequently, the original fiber of about $12 \mu \mathrm{m}$ (see Table I) provides birefringent filaments much smaller (of around $3 \pm 1 \mu \mathrm{m}$ ) which cause a network-like fibrous structure that endorses a higher contact with the CEO matrix. This better interaction with CEO will be reflected in the whole spectra of properties in CEOK5. A further and deeper analysis about how nucleation and the overall crystallization takes place is not possible due to the small size of the crystallites, though, it has to be said that transcrystallization is not occurring for any of the distinct fibers analyzed due to, probably, the different chemical composition of the matrix and fibers.

Figure 5 shows the DSC melting curves of the different samples, normalized taking into account the actual 


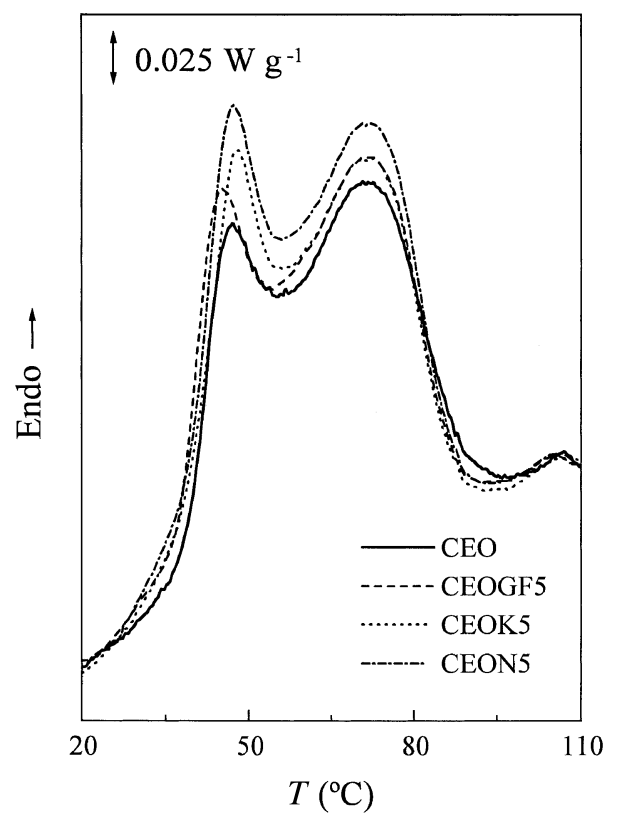

Figure 5. DSC first melting curves for the different samples at a heating rate of $8^{\circ} \mathrm{C} \mathrm{min}^{-1}$. Curves has been normalized considering the actual amount of copolymer in the composites.

amount of polymeric matrix within the composite. The shape of the curves is rather similar for all of the specimens. Two different endothermic processes are observed: one at lower temperature, associated with the melting of crystallites annealed during the stay of the material at room temperature after processing, and the other one, at higher temperatures, that corresponds to the main melting endotherm, associated with crystals formed by the classical nucleation-controlled chainfolded lamellar crystals, while the low-temperature one is attributed to those very imperfect, bundle-like crystals, which exhibit almost reversible crystallizationmelting processes. ${ }^{28}$ The location of the principal melting peak occurring at the highest temperature remains practically unaffected by the incorporation of any of the distinct types of fiber. However, a slight higher enthalpy is attained for the different composites compared with the unreinforced copolymer and, consequently, a slight higher crystallinity (Table I), as already observed by the X-Ray data.

The location of the glass transition in polyethylene has been a subject of arguments and, at present, it remains no universal consensus. In the case of ethylene$\alpha$-olefins, differential scanning calorimetry has been used in recent works for the assignment of their glass transition temperature and to analyze the effect of comonomer composition ${ }^{24}$ and the influence of glass fiber incorporation for a given composition. ${ }^{29}$ In the materials under study, a very broad melting process is exhibited, starting just after $T_{\mathrm{g}}$. Accordingly, the glass transition is not easy to be observed by DSC, as seen

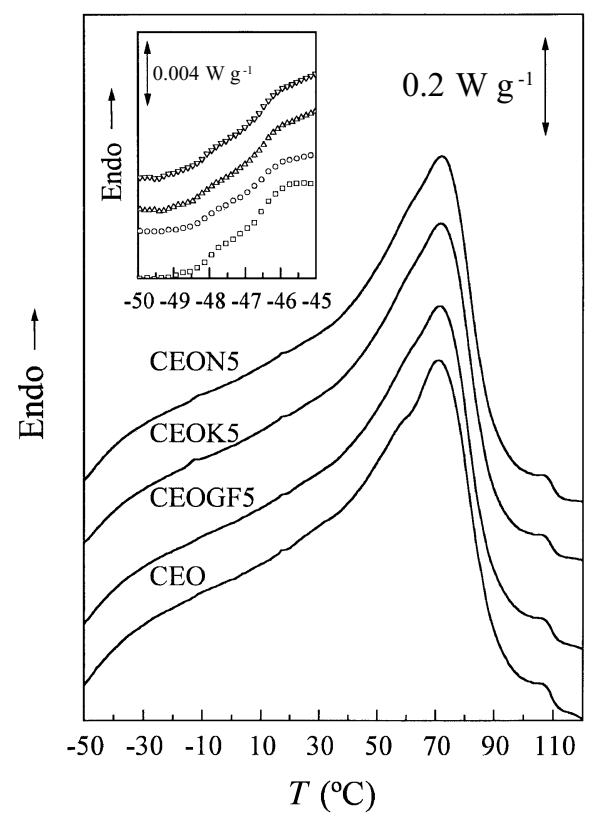

Figure 6. DSC second melting curves corresponding to the copolymer and the different composites, at a heating rate of $20^{\circ} \mathrm{C}$ $\mathrm{min}^{-1}$. From top to bottom: CEON5, CEOK5, CEOGF5 and CEO. In the insert, the glass transition region.

in Figure 6. This figure shows the conventional DSC traces for the copolymer and the different composites, CEOGF5, CEOK5 and CEON5, analyzed at a heating rate of $20^{\circ} \mathrm{C} \mathrm{min}-1$ after a quench. In the insert, a change in the slope of the heat flow at around $-47^{\circ} \mathrm{C}$ for the different specimens is exhibited at this heating rate. It could be attributed either to the glass transition of the copolymer or to the beginning of the melting process of the smallest crystallites. For this particular CEO and its glass fiber composites with fiber content up to $40 \%$, an empirical evidence on the nature of such a change in heat flow has been reported ${ }^{29}$ using modulated DSC joined to the conventional DSC technique, and the mentioned change in slope was associated with the glass transition and not with the melting process, which immediately starts after it, as depicted in Figure 6.

\section{Viscoelastic Behavior}

The dynamic mechanical behavior of polyethylene and related copolymers is strongly influenced by variables that affect the crystalline regions, such as crystallinity, lamellar thickness, and the interface. The incorporation of fibers to the polymeric matrix has provoked some changes in the crystalline phase, such as a slight increase of crystallinity as mentioned above. Moreover, a second interface (matrix/fiber) is present, which is very important from a mechanical point of view. Consequently, differences in the viscoelastic behavior could be expected because of all of these factors. 


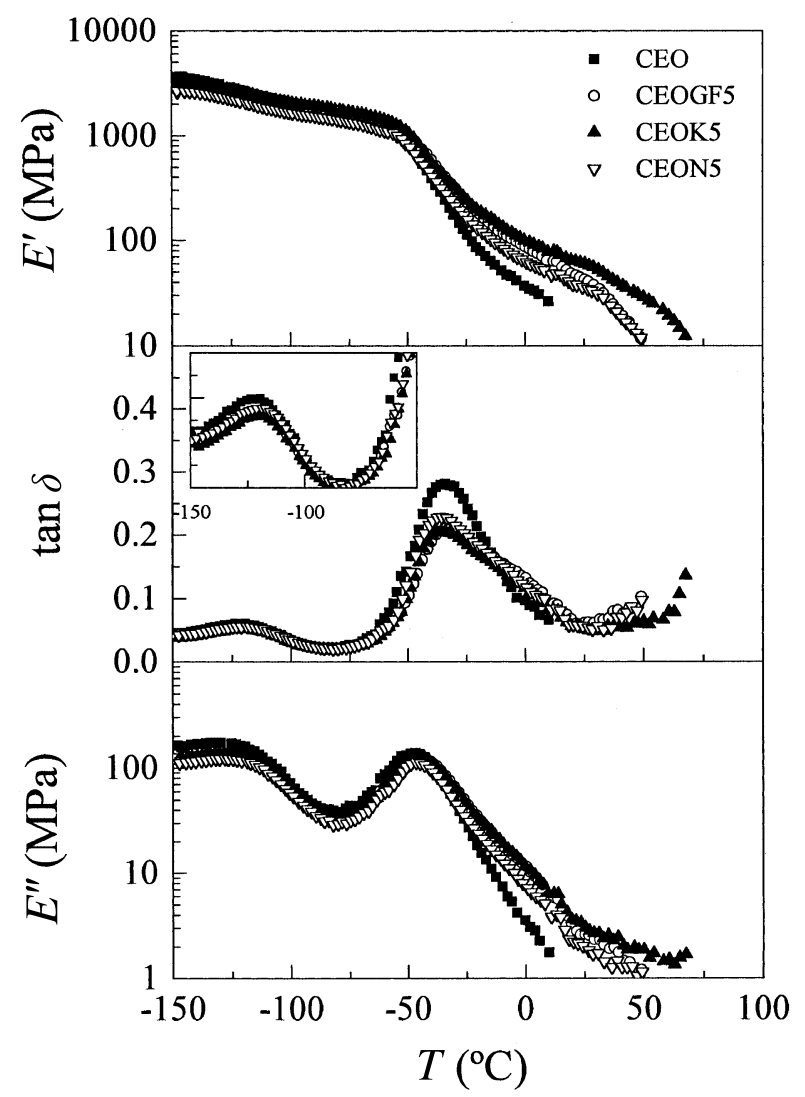

Figure 7. Temperature dependence of the real $\left(E^{\prime}\right)$ and imaginary $\left(E^{\prime \prime}\right)$ components of complex modulus and loss tangent $(\tan \delta)$ of CEO and the distinct composites.

Figure 7 shows the variation of the storage, $E^{\prime}$, and loss, $E^{\prime \prime}$, moduli and of the loss tangent for all the specimens. In the upper part of this figure, it is observed that there is not a clear dependence of $E^{\prime}$ in the different composites at temperatures lower than about $-50^{\circ} \mathrm{C}$ which is about the temperature value obtained for the glass transition measured by DSC, as just commented. However, once above the glass transition region, $E^{\prime}$ values are dependent upon the type of fiber because of the contact between matrix and fiber in that aforementioned second interface. Thus, the plain copolymer, CEO, starts to dramatically lose stiffness at this low temperature. Below the glass transition temperature, either amorphous or crystalline phases provide mechanical resistance to the material. Above $T_{\mathrm{g}}$, a remarkable reduction of modulus is observed, since the contribution of the amorphous component becomes very small. Then, the crystallites, owed to their physical cross-linking and filler effects, ${ }^{30}$ avoid a high plasticity in CEO. However, the low values of both crystallinity and crystallite size make that $\mathrm{CEO}$ does not exhibit mechanical strength under tension ${ }^{25}$ at temperatures higher than $10^{\circ} \mathrm{C}$. On the contrary, the rigidity introduced by the fiber allows the composites to considerably enhance their stiffness at higher temperatures and, consequently, to increase their resistance to creep under stress up to $20^{\circ} \mathrm{C}$ below melting for the composites CEOGF5 and CEON5, and up to the melting for CEOK5. Moreover in CEOK5, a better interaction between the fiber, Kevlar ${ }^{\circledR}$, and matrix, stemming from the peeling process undergone by the fibers, provokes that CEOK5 exhibits the highest mechanical resistance in comparison with the other two composites being nearly entirely molten the crystals at the final temperatures of experiment, as seen in Figure 7 and demonstrated from the optical microscopy results. Fibers keep the integrity of the material at those high temperatures where the matrix has not strength, being $\operatorname{Kevlar}^{\circledR}$ the most effective one from the different types analyzed. In any case, the incorporation of the fibers may enlarge substantially the service temperature range by preventing an undesirable premature softening.

The differences in stiffness have been also checked by microhardness measurements. The MH values for the different samples are shown in the last column of Table II. It can be observed that no differences are found, except for sample CEOK5, which displays a significantly larger $\mathrm{MH}$ than the other specimens because of the better matrix/fiber connection. It has to be considered, however, that MH involves a complex combination of mechanical parameters (elastic modulus, yield strength, strain hardening, toughness), and at these rather small fiber compositions the $\mathrm{MH}$ values is dominated by the properties of the matrix. Anyway, the highest $\mathrm{MH}$ value is found in CEOK5, in agreement with storage modulus values (Figure 7). It seems that for practically the same total crystallinity than in the other two composites, a better adhesion between matrix/ fiber has occurred, improving the mechanical resistance (Figure 4).

Moreover, $\mathrm{MH}$ measurements have been used as a fast method of determining inhomogeneities caused during the processing of polymers and composites materials. ${ }^{31-33}$ In the present case, the distribution of fiber within the copolymeric matrix seems to be quite uniform, being the standard deviations lower than $6 \%$. If we had important inhomogeneities in the samples, those regions rich in fibers will exhibit a significantly higher $\mathrm{MH}$ value.

The effect of the fibers is also observed in loss tangent and loss modulus plots (Figure 7). As common feature for all the specimens, the loss tangent representations show a relaxation process at very low temperatures ( $\gamma$ relaxation) followed by a plateau region and an additional $\beta$ mechanism. A slight asymmetry of this $\beta$ relaxation in the composites points out an overlapping of this relaxation with other viscoelastic process, labelled as $\alpha$. Loss modulus data provide similar information than $\tan \delta$. Thus the $\gamma$ and $\beta$ relaxations are 
Influence of Different Fibers in Composites of a Metallocenic Copolymer

Table II. DSC glass transition temperatures, DMTA results (relaxation temperatures, in $E^{\prime \prime}$ basis at $3 \mathrm{~Hz}$, and activation energies for the different relaxation processes) and microhardness values for the metallocene ethylene-1-octene copolymer and its composites with the different fibers

\begin{tabular}{|c|c|c|c|c|c|c|c|c|}
\hline \multirow[b]{2}{*}{ Sample } & \multirow{2}{*}{$T_{\mathrm{g}}{ }^{\mathrm{DSC}} /{ }^{\circ} \mathrm{C}$} & \multicolumn{3}{|c|}{$T /{ }^{\circ} \mathrm{C}$} & \multicolumn{3}{|c|}{$\Delta H / \mathrm{kJ} \mathrm{mol}^{-1}$} & \multirow[b]{2}{*}{$M H / \mathrm{MPa}$} \\
\hline & & $\gamma$ & $\beta$ & $\overline{\alpha^{\mathrm{a}}}$ & $\gamma$ & $\beta$ & $\alpha$ & \\
\hline CEO & -47 & -132 & -48 & - & 45 & $\sim 200$ & - & 4.5 \\
\hline CEOGF5 & -47 & -129 & -44 & $(-4)$ & 50 & $\sim 200$ & - & 4.5 \\
\hline CEOK 5 & -47 & -128 & -45 & $(-4)$ & 50 & $\sim 200$ & - & 6.1 \\
\hline CEON5 & -47 & -129 & -46 & $(-4)$ & 50 & $\sim 200$ & - & 4.5 \\
\hline
\end{tabular}

${ }^{\mathrm{a}}$ Tentatively assigned.

also observed. Moreover, the overlapping of the $\beta$ and $\alpha$ processes is again exhibited.

$E^{\prime \prime}$ and $\tan \delta$ curves are usually described as composed by contribution of different Gaussian curves, one for each observed relaxation process. Such a convolution does not have a theoretical basis that can explain satisfactorily the shape of the dependence of both magnitudes on temperature, though some factors that can influence them are known. A method of curve convolution to analyze the dynamic mechanical loss curves in the region of the glass transition of several polymers has been proposed ${ }^{34}$ confirming the validity of this empirical approximation. This convolution is a very useful tool for the estimation of relative areas of the different relaxation mechanisms and for the assessment of $\beta$ and $\alpha$ relaxation location when the overlapping of both processes is very important, as occurred in the composites under study. Accordingly, it has been used for the location of the different relaxations that is presented in Table II (together with the values of their apparent activation energies). The observation of the $\alpha$ relaxation for the plain copolymer is hardly discernible though an asymmetry in high temperature side of the $\beta$ process is shown in either $\tan \delta$ or $E^{\prime \prime}$ and an inflection is appearing in the storage mudulus at the same temperature range. The different observed relaxation processes are analyzed separately as follows.

The relaxation appearing at lower temperature in polyethylene, the $\gamma$ relaxation, was firstly attributed to crankshaft movements of polymethylenic chains. ${ }^{35}$ Though a lot of work concerning the $\gamma$ relaxation in polyethylene has been done, there remains no clear consensus regarding the details of the underlying motional process. ${ }^{36,37}$ There is, however, a body of opinions which support one or more of the various models for restricted conformational transitions as kink formation, inversion and migration. ${ }^{38-40}$ Molecular dynamics simulations have been a powerful tool to corroborate the just mentioned nature of these conformational motions underlying this relaxation. ${ }^{41,42}$ This type of motion requires chains containing sequences of three or more methylenic units. As Table II reports and Figure 7 displays, a shift to higher temperatures of the $\gamma$ relax- ation is observed in the composites, and the intensity of such a process decreases with the reinforcement introduction since this relaxation is taking place in the amorphous phase and the content of such a phase has diminished by the fibers incorporation. In addition, the apparent activation energy associated to this mechanism is also dependent upon the fibers. Its value increases slightly in the composites because of the reduction of flexibility.

Regarding the $\beta$ relaxation, it has been universally detected in branched polyethylenes at temperatures around $-20^{\circ} \mathrm{C}$, but it sometimes appears, though weakly, in some samples of linear polyethylene. From the study of various polyethylenes and their copolymers, some authors have concluded that this relaxation results from motions of chain units in the interfacial region ${ }^{43,44}$ whereas some others attributed this process to the glass transition. ${ }^{42,45,46}$ By DSC, the glass transition temperature of the plain copolymer and the composites under study is $-47^{\circ} \mathrm{C}$ (Table II) which has been corroborated ${ }^{29}$ by modulated DSC in CEO and CEOGF5. The agreement between the temperature location of the $\beta$ relaxation and the DSC values for the glass transition, joined to with the pronounced decrease on $E^{\prime}$ through this relaxation, and the relatively high values of the apparent activation energies, are in favor of the assignment of this $\beta$ relaxation to the glassy-rubbery transition in these samples. On the other hand, a shift of this relaxation process to higher temperature and a diminution in $\tan \delta$ of its intensity are observed in the composites because of the mobility constraints caused by fibers. The apparent activation energy values are similar to those found in other thermoplastic elastomers with high flexibility in their backbones. ${ }^{47}$

Finally, the $\alpha$ relaxation in polyethylene has been associated to vibrational and reorientational motions within the crystallites. ${ }^{10,48}$ This process is completely overlapped to the $\beta$ relaxation in all the specimens analyzed here, as commented above. Tentative values obtained, as already mentioned, by the deconvolution of $E^{\prime \prime}$ are given in Table II, though its exact location can vary somewhat depending upon the fit parameters. Consequently, no apparent activation values are pro- 
vided for the $\alpha$ relaxation. The temperature location of the $\alpha$ relaxation, $T_{\alpha}$, in polyethylenes has been found to depend very much on the crystal thickness ${ }^{44}$ and therefore $T_{\alpha}$ diminishes considerably with the increase of comonomer content in ethylene copolymers, ${ }^{49}$ since this increase is accompanied by a decrease in crystallite size. Considering the comonomer content in the present CEO copolymer and the crystallite size estimated from the long spacings, the value of around $-4^{\circ} \mathrm{C}$ obtained for $T_{\alpha}$ seems rather reasonable. In fact, a value of $7^{\circ} \mathrm{C}$ (in $\tan \delta$ basis) has been found for the $\alpha$ relaxation in a CEO copolymer with only a $5.2 \mathrm{~mol} \% 1$-octene content, ${ }^{25}$ which exhibits significantly larger crystallinity and crystal size.

Summing up, the introduction of the fibers provokes an appreciable increase in the intensity of the (110) diffraction. Accordingly, crystallinity, assessed from data either by WAXS or DSC, increases somewhat in the composites by comparison with the unreinforced copolymer. For WAXS crystallinity estimations, an additional crystalline phase, different than the orthorhombic one, has been considered for all the different specimens. Moreover, the incorporation of the fibers significantly modifies the stiffness of the copolymer mainly in CEOK 5 because of the better matrix/fiber interaction observed under optical microscopy. This higher rigidity and the slightly higher crystallinity influence the mobility and the arrangements within the material and, consequently, the whole viscoelastic spectra for the different composites. Thus, both the intensity and location of the $\gamma$ and $\beta$ relaxations are dependent on the incorporation of the $5 \%$ in weight fiber content though not too much on the type of fiber. The $\beta$ relaxation is assigned to the glass transition temperature, in agreement with the calorimetric results in these composites. Rigidity is considerably increased in the composites above the glass transition temperature of the copolymer matrix, allowing the analysis of the viscoelastic behavior up to temperatures well inside the melting region of the copolymer crystals, and thus enlarging substantially the service temperature of these composites. Though the composite with the highest mechanical resistance is CEOK5, however, after the analysis here performed, CEOGF5 would be the better option from a practical point of view, since its price is the most competitive and its structural features and properties exhibited, though not the best ones, are rather similar to those found in CEOK5 and CEO5N. For this CEO matrix, the larger useful temperature range for its applicability in CEOK5 does not, probably, justify its higher cost. Only for application with service temperatures around $50^{\circ} \mathrm{C}$, sample CEOK 5 may be the best choice.
Acknowledgments. The financial support of CAM, CICYT and Bulgarian Academy of Sciences/ Spanish Council for Scientific Research (CSIC) (Projects 07G/0038/2000, MAT98-0961-C02-01 and 2001 BG 0003 ) and the supply of the samples by EXXON Chemical, Cristalera Española S. A. and DUPONT Ibérica are gratefully acknowledged. GZ and MLC are grateful to NATO Science Committee and the Ministerio de Educación y Cultura for their respective financial support. The synchrotron work (in the polymer line of Hasylab at DESY, Hamburg) was supported by the IHP Programme "Access to Research Infrastructures" of the European Commission (Contract HPRI-CT-199900040). We thank the collaboration of the Hasylab personnel, and specially Dr. S. Funari and Dr. A. Meyer, responsibles of the polymer beamline.

\section{REFERENCES}

1. V. K. Gupta, "Handbook of Engineering Polymeric Materials", N. P. Cheremisinoff, Ed., Marcel Dekker, New York, N.Y., 1997, chapt. 12, pp 155-165.

2. L. S. Norwood, in "Handbook of Polymer Composites for Engineers", L. Hollaway, Ed., Woodhead Publishing Ltd., Cambridge, 1994, chapt. 1.

3. L. S. Penn, "Handbook of Polymer-Fibre Composites", F. R. Jones, Ed., Longman Scientific \& Technical, Harlow, England, 1994, chapt. 1.

4. J. L. Thomason and A. A. Van Rooyen, J. Mater. Sci., 27, 889 (1992).

5. J. L. Thomason and A. A. Van Rooyen, J. Mater. Sci., 27, 897 (1992).

6. E. Devaux and B. Chabert, Polym. Commun., 31, 391 (1990).

7. J. P. Jog and V. M. Nadkarni, J. Appl. Polym. Sci., 30, 997 (1985).

8. L. Quintanilla, M. Alonso, J. C. Rodriguez-Cabello, and J. M. Pastor, J. Appl. Polym. Sci., 59, 769 (1996).

9. B. Wunderlich, “Macromolecular Physics”, Academic Press, Inc., New York, N.Y., 1980, vol. 3, p 42.

10. N. G. McCrum, G. Williams, and B. E. Read, "Anelastic and Dielectric Effects in Polymeric Solids", Dover Publications, Inc., New York, N.Y., 1991, chapt. 10, p 353.

11. H. Tadokoro, "Structure of Crystalline Polymers", John Wiley \& Sons, Inc., New York, N.Y., 1979.

12. B. Wunderlich, "Macromolecular Physics", Academic Press, Inc., New York, N.Y., 1973, vol. 1, p 97.

13. K. Shirayama, S.-I. Kita, and H. Watabe, Makromol. Chem., 151, 97 (1972).

14. R. Alamo, R. Domszy, and L. Mandelkern, J. Phys. Chem., 88, 6587 (1984).

15. E. Pérez and D. VanderHart, J. Polym. Sci., Part B: Polym. Phys., 25, 1637 (1987).

16. R. G. Alamo, B. D. Viers, and L. Mandelkern, Macromolecules, 26, 5740 (1993).

17. J. Minick, A. Moet, A. Hiltner, E. Baer, and S. P. Chum, J. Appl. Polym. Sci., 58, 1371 (1995).

18. D. L. VanderHart and E. Pérez, Macromolecules, 20, 1902 
(1986).

19. E. Pérez, D. L. VanderHart, Jr., B. Crist, and P. R. Howard, Macromolecules, 21, 78 (1987).

20. E. Pérez, A. Bello, J. M. Pereña, R. Benavente, M. C. Martínez, and C. Aguilar, Polymer, 30, 1508 (1989).

21. D. C. McFaddin, K. E. Russell, G. Wy, and R. D. Heyding, J. Polym. Sci., Part B: Polym. Phys., 31, 175 (1993).

22. R. Androsch, Polymer, 40, 2805 (1999).

23. R. Androsch, J. Blackwell, S. N. Chvalun, and B. Wunderlich, Macromolecules, 32, 3735 (1999).

24. S. V. Eynde, V. B. F. Mathot, M. H. J. Koch, and H. Reynaers, Polymer, 41, 4889 (2000).

25. M. L. Cerrada, R. Benavente, and E. Pérez, J. Mater. Res., 16, 1103 (2001).

26. V. B. F. Mathot, R. L. Scherrenberg, T. F. J. Pijpers, and W. Bras, J. Thermal. Anal., 46, 681 (1996).

27. V. B. F. Mathot, R. L. Scherrenberg, and T. F. J. Pijpers, Polymer, 39, 4541 (1998).

28. A. Alizadeh, L. Richardson, J. Xu, S. McCartney, H. Marand, Y. W. Cheung, and S. Chum, Macromolecules, 32, 6221 (1999).

29. M. L. Cerrada, R. Benavente, E. Pérez, J. Moniz-Santos, and M. R. Ribeiro, Polymer, 42, 7197 (2001).

30. L. E. Nielsen and R. F. Landel, "Mechanical Properties of Polymers and Composites", 2nd ed, Marcel Dekker, Inc., New York, N.Y., 1994.

31. F. J. Baltá-Calleja, D. R. Rueda, R. S. Porter, and W. T. Mead, J. Mater. Sci., 15, 765 (1980).

32. P. A. Engel and M. D. Derwin, in "Microindentation Techniques in Materials Science and Engineering”, P. T. Blau, B.
R. Lawn, Eds., American Society for Testing and Materials, Special Technical Publication 889, Philadelphia, PA., 1986, pp 272-285.

33. D. M. Shinozaki and A. Klauzner, J. Mater. Sci., 26, 5865 (1991).

34. G. Rotter and H. Ishida, Macromolecules, 25, 2170 (1992).

35. T. F. Schatzki, J. Polym. Sci., 57, 496 (1962).

36. R. G. C. Arridge, Rev. Deform. Behav. Mater, 3, 249 (1981).

37. R. H. Boyd, Polymer, 26, 1123 (1985).

38. R. F. Boyer, Rubber Chem. Technol., 36, 1303 (1963).

39. R. H. Boyd and R. S. Breitling, Macromolecules, 7, 855 (1974).

40. R. H. Boyd, J. Polym. Sci., Part B: Polym. Phys., 13, 2345 (1975).

41. R. H. Boyd, R. H. Gee, J. Han, and Y. Jin, J. Chem. Phys., 101, 788 (1994).

42. Y. Jin and R. H. Boyd, J. Chem. Phys., 108, 9912 (1998).

43. R. Popli and L. Mandelkern, Polym. Bull., 9, 260 (1983).

44. R. Popli, M. Glotin, L. Mandelkern, and R. S. Benson, J. Polym. Sci., Part B: Polym. Phys. 22, 407 (1984).

45. R. H. Boyd, Macromolecules, 17, 903 (1984).

46. J. Han, R. H. Gee, and R. H. Boyd, Macromolecules, 27, 7781 (1994).

47. M. L. Cerrada, J. L. de la Fuente, M. Fernández-García, and E. L. Madruga, Polymer, 42, 4647 (2001).

48. I. M. Ward, "Mechanical Properties of Solids Polymers", 2nd ed, John Wiley \& Sons Ltd., Chichester, 1985, chapt. 8, p 166.

49. M. L. Cerrada, R. Benavente, B. Peña, and E. Pérez, Polymer, 41, 5957 (2000). 